\title{
9-三氯基乙烯基葸的光谱性质
}

陈景荣 张宝文 曹 怡

(中国科学院藏光化学研究所, 北京 100101)

\section{关铜 9-三基乙烯基苾、9-三基乙基蓦、裡曲分子内电荷转移（TICT）态}

近年来,一些同时具有电子给体、电子受体的 $\pi$ 电子共轭体系有机化合物引起了人们广泛 的兴酷. 这是因为除了在电子转移及电荷分离的理论研究上有重要的意义外, 这类化合物还 有可能作为新型光电功能材料, 有明确的高技术应用前景 ${ }^{[1,2]}$. 例如, 许多化合物具有扭曲分 子内电荷转移 (TICT) 态, 用这类化合物制作分子器件很可能会产生重要的、特殊的光学及 电学性质出. 但也存在许多问题有待进一步研究 ${ }^{[2,3)}$. 本文对照 9-三氯基乙基葱 (TEA), 讨 论了 9-三基乙烯基葱（TVA）在不同溶剂中的光谱性质。认为在极性溶剂中敫发态时 TVA 可达到 TICT 态,但不发光. 初步测定了 TVA 的一些光电性质, BLM 中测得近 200 $\mathrm{mV}$ 的开路光电压, 有较强的表面光电压信号及三阶非线性光学活性.

\section{一、实验部分}

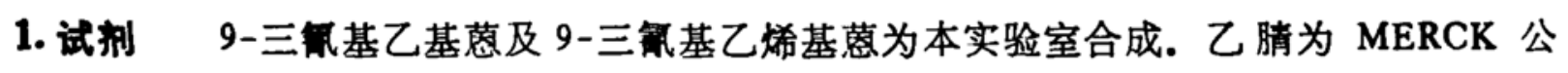
司产品,其它试剂及所用溶剂均为市售分析纯, 经处理后使用 ${ }^{\text {(9.9. }}$.

2. 仪国 UV 从 Hitachi 340 型紫外分光光度计获得. 用 Hitachi MPF-4 荧光光谱 仪测定荧光光谱. 用 SP 型毫微秒荧光光谱仪通过单光子计数法测定激发单重态的寿命. 测 定前通氮气饱和 $15 \mathrm{~min}$.

\section{二、结果与讨论}

1. 吸收光请与苂光光请 测定了 TVA 和 TEA 的吸收光谱与荧光光谱, 对比二者光 谱的异同来讨论 TVA 分子内的电子转移.

图 1 清楚地表明 TEA 的吸收光谱和苂光光谱互成镜影与一般取代牭的光谱行为一 致. 它的吸收及苂光光谱在不同极性溶剂中的形状、位置、 $\varepsilon$ 及荻光量子产率都相差无几.在乙腈、 $\mathrm{CCl}_{4}$, 及正庚烷三种不同极性溶剂中的苂光寿命分别为 $13,11.6,11.5 \mathrm{~ns}$ 也很接近.

TVA 的光谱(图 2) 则大不相同, 其吸收光谱明显地分成两个部分, $330-390 \mathrm{~nm}$ 是葱部 分的特征, 495-550nm 的吸收是 TVA 整个分子的吸收.

我们测定了 11 种溶剂中 TVA 的吸收光谱, 其 $\lambda_{\text {max }}$ 随溶剂极性增加变化不大, 而摩尔 消光系数 $\varepsilon$ 随极性增大而变小. 另外,随溶剂极性增大, 在 495-550nm 长波方向的吸收峰由 两个变成一个无结构的宽峰。一般来讲, 任何使分子失去平面的作用即分子体系的任何扭曲

本文1990年9月27日收到. 1991 年3月7日收到修改椋. 


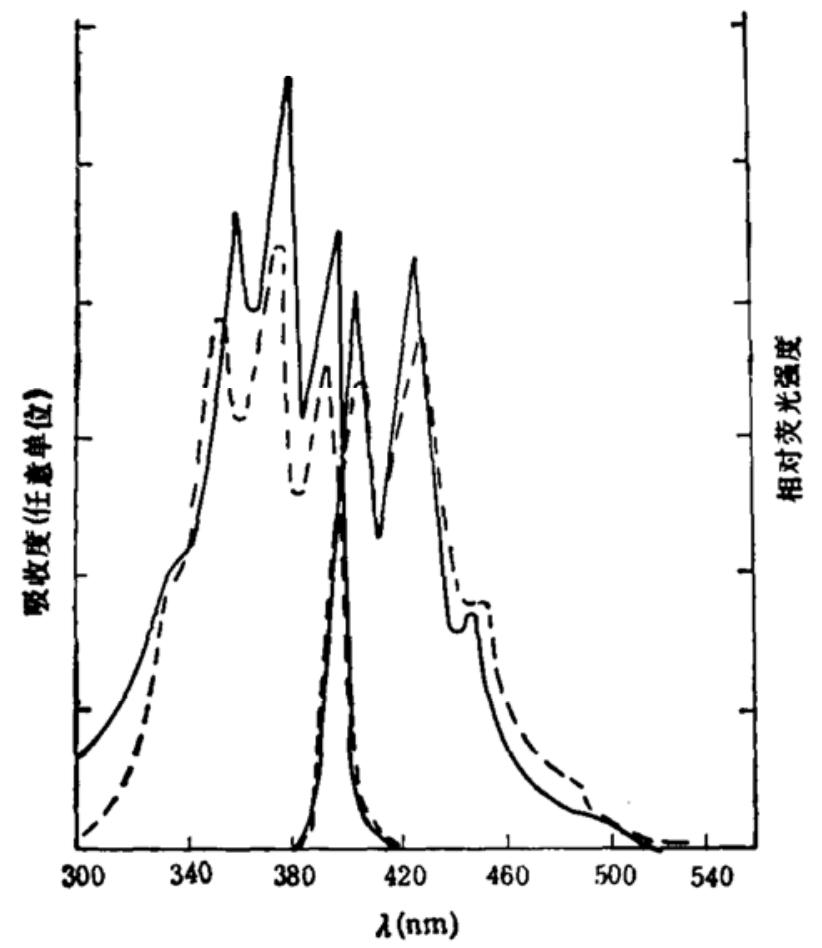

图 1 TEA 的吸收及苂光光谱 一正庚㛡； …… 亿随

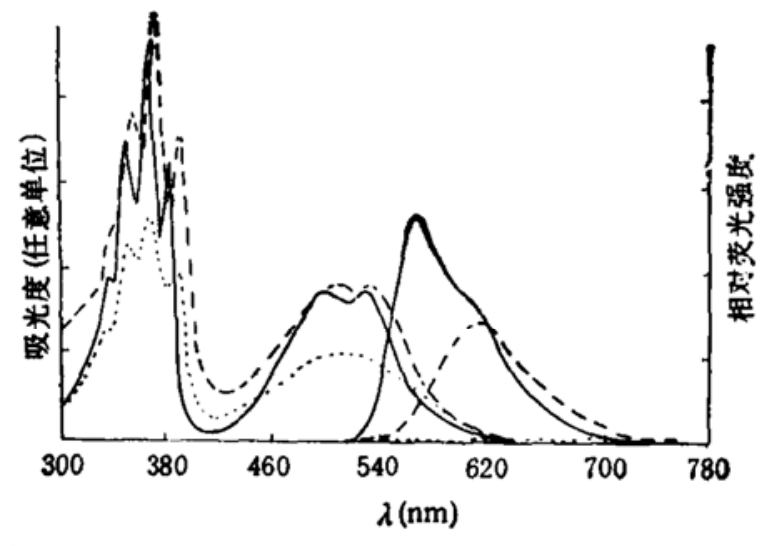

图 2 TVA 的吸收光谱及苂光光谱

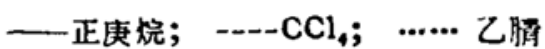

都会使分子失去共轭, 而 8 相应地降低并失去精细结构 ${ }^{[s]}$, 这说明 TVA 分子在基态时随着极 性增大分子平面性变差.

表 1 TVA 在不同溶剂中的荧光光谱

\begin{tabular}{|c|c|c|}
\hline 溶 剂 & $E_{\text {oose }}(\mathrm{nm})$ & 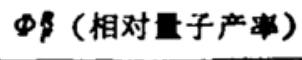 \\
\hline 正 戊 烷 & 568 & 2.44 \\
\hline 正 己 㜔 & 570 & 1.89 \\
\hline 正 庚 烷 & 572 & 2.33 \\
\hline 异辛熍 & 572 & 1.78 \\
\hline 四里化碝 & 620 & 1.00 \\
\hline 苯 & - & 0.00 \\
\hline
\end{tabular}

从表 1、图 2 中可发现 rVA 分子的荻光光谱随极幽改变有着极大的变化. 已经完全看 不到蓦基的茨光, 在长波方 向出现了一个新的荻光峰. 在极性小的烷烃溶剂中荧光光谱的 $\boldsymbol{E}_{\lambda \max }$ 在 $570 \mathrm{~nm}$ 左右, 相对量子产率相差不多. 四氯化碳比烷烃极性略有增加其 $E_{\lambda \max }$ 红移 至 $620 \mathrm{~nm}$ ，相对茨光量子产率绛低大约一倍，而在极性大于 $\mathrm{CCl}$ ，的溶剂中检测不到荻光.

TEA 和 TVA 这两个化合物的光谱性质有如此大的区别,主要是由于它们在结构上的不 同. 化合物 TVA 整个分子是共轭的, 在葱 9 位上的取代基是受电子的生色团一三三基乙 烯基, 而 TVA 在苾的 9 位上只是一个吸电子取代基一三基乙基. 因此.在一定条件下, TVA 分子的葱基及三涾基乙烯基两部分之间能发生分子内电荷转移及电荷分 离而 TEA 则 不可能.

Al-Hassan 等人对连芳基化合物的特殊光谱性质进行了研究 ${ }^{[6]}$, 认为由于空间位阻, 基态 分子不处在同一个平面,因此, 在基态时偶饩矩为 0 , 分子强烈扭曲,两个芳基之间的夹角大约 
为 $90^{\circ}$, 受光敫发到 LE 态时, 它的几何构型发生改变, 变得更共平面一些, 在 $70^{\circ}$ 左右, 此时 如果在极性溶刹中, 电子就可以由一个芳基转移到另一个芳基上,尔后二者又呈几乎垂直的几 何构型以降低能量,稳定分子,达到能量较 LE 态低的 TICT 态. TICT 态极性很大, 其苂 光也随极性有很大红移. 用 Sybyl 程序,计算机模拟，结果是 TVA 的蓦基与三氞基乙烯基 部分不能共平面, 二面角大约 $90^{\circ}$ 时分子能量最低,类似于连芳基化合物. 从其 $\lambda_{\max }$ 随极性 没有明显改变,可说明基态偶极矩不大. 但到了单重敫发态,分子几何构型改变, 两部分更趋 于平面,极性溶剂中葱基很容易把一个电子传给三㖇基乙烯基部分,随后两部分呈几乎垂直的 几何构型即 TICT 态,达到有效的电荷分离. 由于其 TICT 态极性很大, 不难理解 TVA 的 荧光随极性有极大变化. 非极性烷烃溶剂中 570 nm 的荧光来自 LE 态, 在极性溶剂中检测 不到苂光, 这是由于 TICT 态不发光 ${ }^{\text {m. 从 }}$ 从 TVA 表现出的良好光电性质反过来也说明该分 子在激发态时达到了有效的电荷分离(见第 2 部分).

2. 光电性质 由于 TVA 能吸收长达 $600 \mathrm{~nm}$ 的可见光, 基态时极性小, 但到单重敨发 态时由于分子内电荷转移, 可驰豫到 TICT 态, 达到有效的电荷分离. 具有这类性质的化合 物有可能作为光电功能材料. 我们初测了 TVA 的一些光电性质: (1) 在双分子 类 脂 膜 (BLM) 中测得开路光电压可高达 $200 \mathrm{mV}$; (2) 三阶非线性 $x^{3}$ 为 $10^{-9}-10^{-10} \mathrm{esu}$; (3) 有较强 的表面光电压信号、形状与固态的吸收光谱非常近似.

致讨: 感谢 NAMCC 资助. 感谢吉林大学化学系本铁侓教授实验室测试表面光电压和吉林大学物理 系费浩生教授调式三阶非线性. 对中国科学院感光化学研究所俞稼廉教授实验室测试 BLM 中的开路光电 压表示谢意.

\section{$\Rightarrow$ 文 常}

[1] Rettig, w., Appl. Phys., BAS (1988), 145.

[2] Wang, Y., Chem. Soc. Paraday Trans. 2, 84 (1988), 11:1890.

[3] Rettig, W., Angew. Chem. Int. Ed. Engl., 25(1986), 971.

[4] Perrin, D. D., Armargo, W. L. F. and Perrin. D. R., Purification of Laboratory Chemicals. Pergamon Press, Oxford, 1966, 59.

[5] Jurkowitz, L.. Loeb, J. N., Brown. P. K. et al., Natwre, 1959, 4686:614.

[6] Al-Hassan, K. and Azumi, T., Chem. Phys. Lost.. 150(1988), 3/4: 344.

[7] Shin, D. M. and Whitten, D. G., J. Phys. Chem., 92(1988), 2945. 